\title{
Deducing Multidecadal Anthropogenic Global Warming Trends Using Multiple Regression Analysis
}

\author{
JiANSONG ZHOU AND KA-KIT TUNG \\ Department of Applied Mathematics, University of Washington, Seattle, Washington
}

(Manuscript received 20 July 2012, in final form 9 October 2012)

\begin{abstract}
To unmask the anthropogenic global warming trend imbedded in the climate data, multiple linear regression analysis is often employed to filter out short-term fluctuations caused by El Niño-Southern Oscillation (ENSO), volcano aerosols, and solar forcing. These fluctuations are unimportant as far as their impact on the deduced multidecadal anthropogenic trends is concerned: ENSO and volcano aerosols have very little multidecadal trend. Solar variations do have a secular trend, but it is very small and uncertain. What is important, but is left out of all multiple regression analysis of global warming so far, is a long-period oscillation called the Atlantic multidecadal oscillation (AMO). When the AMO index is included as a regressor (i.e., explanatory variable), the deduced multidecadal anthropogenic global warming trend is so impacted that previously deduced anthropogenic warming rates need to be substantially revised. The deduced net anthropogenic global warming trend has been remarkably steady and statistically significant for the past $100 \mathrm{yr}$.
\end{abstract}

\section{Introduction}

The observed global warming rate is nonuniform. After a period of cooling in the 1960s and 1970s, global warming accelerated until 2005 (Solomon et al. 2007). The most recent speculation concerns the possible "stalling" of the rate of warming of the global-mean surface temperature. As shown in Fig. 1 in Foster and Rahmstorf (2011), 1998 was the warmest year in some datasets [such as the Climatic Research Unit (CRU)], while in others it was 2005 or 2010 [the National Climatic Data Center (NCDC) or the Goddard Institute for Space Studies (GISS)]. Undoubtedly, short-term natural climate fluctuations play a role: The "super" El Niño in 1998 made that year either the warmest or close to the warmest on record, and the La Niña in 2008 contributed to that year being not as warm. It is understood that these, and possibly other, natural fluctuations should be filtered out to reveal the underlying anthropogenic warming. Multiple linear regression (MLR) analysis is often employed for this purpose. Typical regressors (also called explanatory or predictor variables) are El

Corresponding author address: Ka-Kit Tung, Department of Applied Mathematics, University of Washington, Box 352420, Seattle, WA 98195-2420.

E-mail: tung@amath.washington.edu
Niño-Southern Oscillation (ENSO), volcano aerosol optical depth, total solar irradiance (TSI) (11-yr solar cycle plus the secular solar forcing trend), and the anthropogenic warming trend. These are specified as a function of time. MLR is used to fit the observed temperature time series using these regressors, with the residual assumed to be a white or red noise. When the residual is tested to be a noise, the MLR provides an explanation of the observed time series as being composed of these known variations plus climate noise.

The response to anthropogenic forcing should include that because of the increase in carbon dioxide and other greenhouse gases as well as anthropogenic tropospheric aerosol ("pollution"), which tends to cool to yield a net warming smaller than that produced by greenhouse gases alone. There are two approaches to constructing the net anthropogenic warming regressor. One approach, typified by the work of Lean and Rind (2008), constructs the time series of anthropogenic regressor from an inventory of greenhouse gas concentrations, tropospheric aerosols, and land surface plus snow albedo changes, and was the same as that used in the GISS model for simulating twentieth-century climate (Hansen et al. 2007). This approach predetermines the time behavior of the anthropogenic warming, even though the uncertainty in the tropospheric aerosol is high. This construction yields a strong anthropogenic warming rate 
after 1978 from a much slower pace before that. Their conclusion that the anthropogenic warming rate has accelerated, from the $50-\mathrm{yr}$ trend of $0.136^{\circ} \pm 0.003^{\circ} \mathrm{C}$ decade $^{-1}$ to the 25 -yr trend of $0.199^{\circ} \pm 0.005^{\circ} \mathrm{C} \mathrm{decade}^{-1}$, is a direct consequence of the shape in time of the anthropogenic regressor used. To answer specifically whether the anthropogenic warming has slowed in recent years, Foster and Rahmstorf (2011) take a second approach. They replaced the anthropogenic time series by a linear function of time. The linear trend is determined by the MLR process. Then, the regressed linear trend is added back to the residual and the sum is displayed. They called this sum the "adjusted data." If the anthropogenic warming rate is nonuniform, then it should show up as such in the sum. Nevertheless, they found that the anthropogenic warming rate has been "remarkably steady" for the period analyzed, 1979-2010. We shall first use this second approach and reexamine the deduced anthropogenic warming rate. This approach has the advantage of not predetermining the answer, allowing for the possibility that we may not know how to construct the anthropogenic forcing index precisely.

\section{The residual in the multiple regression analysis}

Foster and Rahmstorf (2011) studied five datasets: three surface temperature records and two satellite records. The anthropogenic warming rates are found to be consistent with each other. The 32-yr trend for the adjusted global-mean surface temperature from the Hadley Centre and Climate Research Unit surface temperature, version 3, (HadCRUT3v) is $0.170^{\circ} \mathrm{C} \mathrm{decade}^{-1}$. The results are approximately the same using other surface temperature records: GISS at $0.171^{\circ} \mathrm{C}$ decade $^{-1}$ and $\mathrm{NCDC}$ at $0.175^{\circ} \mathrm{C}$ decade $^{-1}$. We have repeated their analysis for the short period of 1979-2010 and found very similar results. The results shown here are for the longer period of 1856-2010 using the latest global-mean data HadCRUT4 (Morce et al. 2012).

The explanatory variables used in our analysis include the TSI, volcano aerosol optical depth (Sato et al. 1993), cold tongue index (CTI) for the ENSO effect (available at http://jisao.washington.edu/data/cti/), and a linear trend. Since we do not know the shape of the anthropogenic response, a linear trend of warming is used as an initial guess. It will be added back to the residual to determine the final response. The MLR analysis can also be done without an anthropogenic regressor. Then the anthropogenic warming rates determined from the residual will be about $10 \%$ higher. The multivariate ENSO index (MEI) that Foster and Rahmstorf (2011) used is available only for the recent decades, and so we used the cold tongue index instead, which is available for the longer record that we will be examining. We characterize the solar variability by the TSI reconstruction up to 2009 based on Wang et al. (2005). Its recent values are filled in using the daily measurements from the Total Irradiance Monitor (TIM) on the National Aeronautics and Space Administration's (NASA's) Solar Radiation and Climate Experiment (SORCE) (available from http://lasp.colorado.edu/sorce/data/tsi_data.htm; Kopp and Lean 2011). We do not use a sinusoid with an annual period as a regressor as in Foster and Rahmstorf (2011). The noise model is adaptive autoregressive (AR) noise of order $p[\operatorname{AR}(p)]\{$ vs their autoregressive movingaverage $[\operatorname{ARMA}(1,1)]$ model $\}$.

Figure 1a shows the adjusted data (with ENSO, volcano aerosols, and solar influence removed) for the longer period of 1856-2010, following the analysis of Foster and Rahmstorf (2011). The recent 32-yr trend is found to be $0.169^{\circ} \pm 0.019^{\circ} \mathrm{C} \mathrm{decade}^{-1}$, very close to that found by Foster and Rahmstorf (2011). It also seems to be remarkably steady, with no acceleration or stalling of the global warming trends. However, over the extended 160 -yr period, one can clearly see that there is a longperiod oscillation still present in the residual. The running-time mean (blue) reveals a 70-yr oscillation in the global-mean temperature of a significant structured variation of $0.3^{\circ} \mathrm{C}$ that has not been "explained" by the MLR analysis. This oscillation happens to be in a positive half cycle during the $32 \mathrm{yr}$ analyzed by Foster and Rahmstorf (2011). Possibility exists that the oscillation was treated as a trend in the shorter record.

Folland et al. (1984) and Schlesinger and Ramankutty (1994) were the first to point out that there is a multidecadal oscillation in the global-mean-temperature record. Wu et al. (2011), using the method of empirical mode decomposition (Wu and Huang 2009; Huang et al. 1998), found that this mode has a period of $65 \mathrm{yr}$ in the 150-yr global-mean temperature. They called this mode the Atlantic multidecadal oscillation (AMO), following the previous work of Delworth and Mann (2000) that this global-mean oscillation has its origin in the North Atlantic. They further showed the impact that this mode has on the perceived global warming trend: when the AMO is removed as an oscillatory mode, the remaining trend is smaller, at $0.08^{\circ} \mathrm{C}$ decade ${ }^{-1}$ since 1980 .

\section{A new multiple regression analysis}

The inset of Fig. 1a shows the detrended running-time mean in the adjusted data from Fig. 1a (blue) against the AMO index (Enfield et al. 2001), which is defined as the detrended sea surface temperature averaged over the North Atlantic. We see that the two follow each other closely. Fig. 1b shows the result when we repeat 

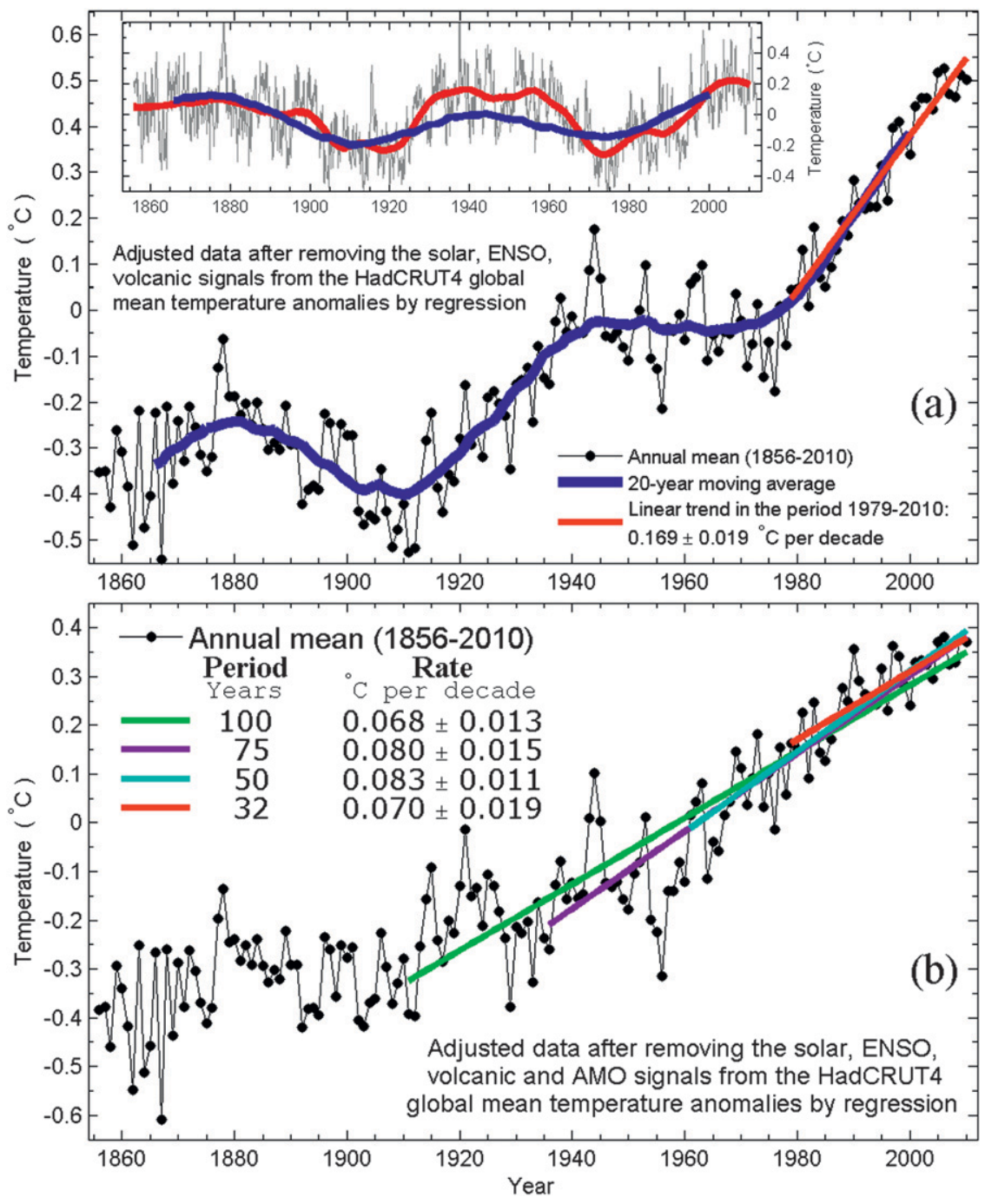

FIG. 1. (a) Adjusted global-mean annual-mean temperature for the period 1856-2010, after ENSO, volcano aerosol, and solar influences have been removed by regression. The order of the noise is found to be $p=4$. The 20-yr moving average is shown in blue, and the linear trend is fitted to the period 1979-2010 in red. The inset shows the detrended running-time mean of the adjusted data in Fig. 1a in blue. The AMO index to be used later in the MLR is in red. The thin line is the raw monthly AMO index from http://www.esrl.noaa.gov/psd/data/timeseries/AMO/. The red curve is a smoothed version of it using a modified running-time mean, called locally weighted scatterplot smoothing (LOWESS), that allows the mean index to be extended to the beginning and end of the record of the monthly data. Quadratic fitting over a $25-\mathrm{yr}$ period is used. Time lags are found to be 5 months for volcano and ENSO responses. (b) Adjusted global-mean annual-mean temperature, after ENSO, volcano, solar, and AMO influences have been removed by regression; $p=2$.

the MLR analysis, but it now includes the smoothed AMO index as an additional regressor (http://www.esrl. noaa.gov/psd/data/timeseries/AMO/). The global-mean temperature adjusted this way shows mostly a monotonic trend with some scatter. This anthropogenic warming has been remarkably steady since 1910 . The 100 -yr trend is $0.068^{\circ} \pm 0.013^{\circ} \mathrm{C}$ decade ${ }^{-1}$, the 75 -yr trend is $0.080^{\circ} \pm 0.015^{\circ} \mathrm{C}$ decade ${ }^{-1}$, and the $50-\mathrm{yr}$ is $0.083^{\circ} \pm 0.011^{\circ} \mathrm{C}$ decade $^{-1}$. The $32-\mathrm{yr}$ trend now is $0.070^{\circ} \pm 0.019^{\circ} \mathrm{C}$ decade $^{-1}$, which is less than one-half the value found by Foster and Rahmstorf (2011) and almost one-third the value found by Lean and Rind (2008). It is consistent with the findings of $\mathrm{Wu}$ et al. (2011). Our linear trends are found to be statistically significant and deterministic according to the Woodward and Gray (1995) test. 
We do not wish to conclude that the anthropogenic warming rate has slowed, from the 50 -yr trend of $0.083^{\circ} \mathrm{C}$ decade $^{-1}$ to the $32-y r$ trend of $0.070^{\circ} \mathrm{C}_{\text {decade }}{ }^{-1}$. When the error bars are taken into account, there is no basis for that conclusion. The conclusion that we can draw is that for the past $100 \mathrm{yr}$, the net anthropogenic trend has been steady at approximately $0.08^{\circ} \mathrm{C} \mathrm{decade}^{-1}$.

\section{Justification for including the AMO as a regressor}

The remaining question is whether the AMO is a natural oscillation or the response to a time-varying anthropogenic forcing. Recently Booth et al. (2012) simulated $76 \%$ of the two cycles of the AMO in the industrial era using the Earth system model version of the Hadley Centre Global Environmental Model (HadGEM2-ES) and attributed the North Atlantic variability to the indirect effect of anthropogenic aerosol's time-varying forcing. However, Zhang et al. (2013) pointed out that the indirect aerosol effects in Booth et al. (2012) are probably overestimated, and the time and spatial signatures in the model's upper ocean are contrary to the observed.

Using $330 \mathrm{yr}$ of multiproxy data of near-global coverage, Delworth and Mann (2000) found almost 4.5 cycles of the AMO, with 2 cycles in the preindustrial era. Tung and Zhou (2012, manuscript submitted to Proc. Natl. Acad. Sci. USA) found 5 cycles of 70 -yr oscillation in the world's longest instrumental temperature record from central England. These long records argue in favor of the natural and recurrent nature of the AMO. The variability appears to be caused by fluctuations in the thermohaline circulation (Dima and Lohmann 2007; Delworth and Mann 2000; Enfield et al. 2001; Knight et al. 2005; Schlesinger and Ramankutty 1994; Wei and Lohmann 2012; Semenov et al. 2010).

There are a couple realizations of a coupled atmosphereocean general circulation model calculation containing an AMO of the right phase as the observed (Delworth and Knutson 2000; Delworth and Mann 2000), but many other realizations that do not. So when ensemble averaged, this internal variability is much reduced. Nevertheless, it shows that some models can produce such a multidecadal oscillation without anthropogenic forcing. To circumvent the known difficulty of model internal variability not always of the right phase and amplitude as the one realization that is our observed world, DelSol et al. (2011) analyzed the control runs of the coupled atmosphere-ocean general circulation models in phase 3 of the Coupled Model Intercomparison Project (CMIP3) archive (Meehl et al. 2007). They found, by maximizing the average predictability time, a dominant spatial pattern that they called the internal multidecadal pattern, which is centered at the North Atlantic but also extends to the Pacific. When the global temperature data are projected onto this spatial pattern, they obtain 2.5 cycles of a multidecadal oscillation very similar to the AMO index. Their result suggests that the oscillation is not anthropogenically forced.

\section{The shape of the anthropogenic regressor}

We argue that the time shape of the anthropogenic forcing used by Lean and Rind (2008) is not consistent with the observed anthropogenic response (see Fig. 2a). The evidence is in the residual of their MLR, which was not shown by them. Compared to the almost linear behavior of the deduced anthropogenic trend in our Fig. 1b, their assumed trend accelerated after the 1970s. The residual of the MLR analysis repeated by us using monthly HadCRUT4 global-mean temperature is shown in Fig. 2b [the result is similar using HadCRUT3v, except for the much sharper data discontinuity in 1945 that was not yet corrected in version 3 (Thompson et al. 2008)]. The residual, which should only consist of climate noise if the MLR is successful, shows a negative trend after 1970 and a positive trend before that time, suggesting that their regressor for anthropogenic forcing is increasing too rapidly after 1970 and too slow before that time. When the MLR analysis is repeated with a consistent anthropogenic regressor, the warming rates converge to those in Fig. 1b. Since the MLR analysis depends critically on the time behavior of the regressors assumed, the spatial pattern deduced could be wrong if the real anthropogenic warming rate is not the same as what was assumed. One of the highlighted results of Lean and Rind's MLR analysis is that the deduced spatial patterns of anthropogenic warming and solar forcing "differ distinctly" from those indicated by the Intergovernmental Panel on Climate Change (IPCC). In particular, instead of finding polar amplification of warming, which is a robust feature across IPCC models, their deduced warming pattern is more pronounced between $45^{\circ} \mathrm{S}$ and $50^{\circ} \mathrm{N}$ than at higher latitudes.

\section{Conclusions}

It is pointed out that the Atlantic multidecadal oscillation, a likely natural and recurrent phenomenon, has not been taken into account in any multiple linear regression analysis of the global warming trends using observational data in published literature. Yet, over any multidecadal period, the AMO is the most important factor affecting the deduced "anthropogenic trend," since other, shorter-term internal variability, such as 

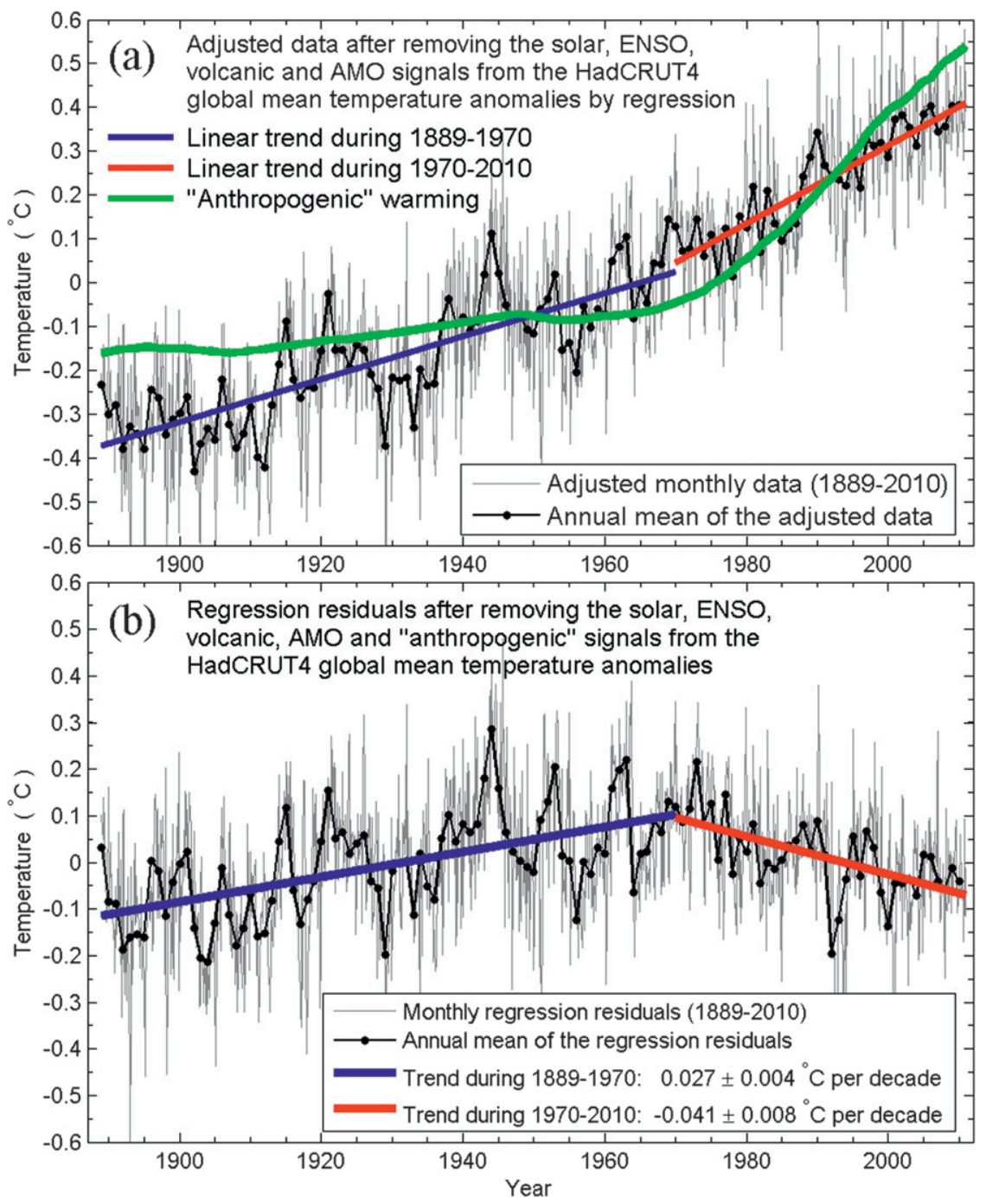

FIG. 2. MLR analysis using the same regressors and time lags, and white-noise model as Lean and Rind (2008), and monthly HadCRUT4 global-mean temperature. (a) The adjusted data after removal of solar, ENSO, volcano, and AMO. It should contain the anthropogenic trend and climate noise. Their prescribed anthropogenic forcing index is superimposed in green. (b) The residual is what remains after removing the regressed effects of ENSO, solar, volcano, AMO, and their prescribed anthropogenic forcing. It should contain only climate noise if the MLR analysis is successful, but there is a negative trend remaining in recent decades (red).

ENSO or volcano aerosols, usually do not contain any multidecadal trend, and solar forcing's secular trend is small. When the AMO is included, in addition to the other explanatory variables such as ENSO, volcano, and solar influences commonly included in the multiple linear regression analysis, the recent 50- and 32-yr anthropogenic warming trends are reduced by a factor of at least 2. There is no statistical evidence of a recent slowdown of global warming, nor is there evidence of accelerated warming since the mid-twentieth century. The anomalous early twentieth-century warming is also explained as being caused by the AMO's upswing on top of the same anthropogenic warming trend. This deduced time behavior of anthropogenic warming is different from that previously constructed by GISS and used by Lean and Rind (2008) in deducing the latitudinal structure of anthropogenic warming.

Tung et al. (2008) had previously suggested that the transient climate sensitivity to increasing greenhouse gases should be higher than in most CMIP3 models. The lower net anthropogenic warming rate found here does not necessarily contradict that result, since the observationally determined net warming includes tropospheric aerosol cooling, which is uncertain but could be 
quite significant in the past decades from industrial pollution.

It is known (Benestad and Schmidt 2009) that the method of MLR may give erroneous attribution for small forcing, and for collinear forcings. Secular solar forcing is small and, with a positive trend, it may be collinear with greenhouse forcing. So this method should not be relied on for attribution of solar response. Fortunately, the solar secular trend is so small that whether it is included in MLR does not affect the other results. Furthermore, MLR is used here only as a means to "adjust" the data, following the approach of Foster and Rahmstorf (2011), that is, to remove fluctuations to better reveal the underlying trend. Whether this method is successful can be judged by the reduced scatter in the adjusted data and by the residual's resemblance to random noise.

Acknowledgments. We thank Dr. Zhaohua Wu for helpful discussions. The research is supported by the NSF under Grants ATM 808375 and DMS 0940342 and by NASA under Grant NNX11AC75G.

\section{REFERENCES}

Benestad, R. E., and G. A. Schmidt, 2009: Solar trends and global warming. J. Geophys. Res., 114, D14101, doi:10.1029/ 2008JD011639.

Booth, B. B. B., N. J. Dunstone, P. R. Halloran, T. Andrews, and N. Bellouin, 2012: Aerosols implicated as a prime driver of twentieth-century North Atlantic climate variability. Nature, 484, 228-232.

DelSol, T., M. K. Tippett, and J. Shukla, 2011: A significant component of unforced multidecadal variability in the recent acceleration of global warming. J. Climate, 24, 909-026.

Delworth, T. L., and M. E. Mann, 2000: Observed and simulated multidecadal variability in the Northern Hemisphere. Climate Dyn., 16, 661-676.

— global warming. Science, 287, 2246-2250.

Dima, M., and G. Lohmann, 2007: A hemispheric mechanism for the Atlantic multidecadal oscillation. J. Climate, 20, 2706-2719.

Enfield, D. B., A. M. Mestas-Nuñez, and P. J. Trimble, 2001: The Atlantic multidecadal oscillation and its relation to rainfall and river flows in the continental U.S. Geophys. Res. Lett., 28 , 2077-2080.

Folland, C. K., D. E. Parker, and F. E. Kates, 1984: Worldwide marine temperature fluctuations 1856-1981. Nature, 310, 670673.

Foster, G., and S. Rahmstorf, 2011: Global temperature evolution 1979-2010. Environ. Res. Lett., 6, 1-8.

Hansen, J. A., and Coauthors, 2007: Climate simulations for 18802003 with GISS modelE. Climate Dyn., 29, 661-696.

Huang, N. E., and Coauthors, 1998: The empirical mode decomposition and the Hilbert spectrum for nonlinear and non-stationary time series analysis. Proc. Roy. Soc. London, 454A, 903-995.
Knight, J. R., R. J. Allan, C. K. Folland, M. Vellinga, and J. E. Mann, 2005: A signature of persistent natural thermohaline circulation cycles in observed climate. Geophys. Res. Lett., 32, L20708, doi:10.1029/2005GL024233.

Kopp, G. and J. L. Lean, 2011: A new, lower value of total solar irradiance: Evidence and climate significance. Geophys. Res. Lett., 38, L01706, doi:10.1029/2010GL045777.

Lean, J. L., and D. H. Rind, 2008: How natural and anthropogenic influences alter global and regional surface temperatures: 1889 to 2006. Geophys. Res. Lett., 35, L18701, doi:10.1029/ 2008 GL034864.

Meehl, G. A., C. Covey, T. Delworth, M. Latif, B. McAvaney, J. F. B. Mitchell, R. J. Stouffer, and K. E. Taylor, 2007: The WCRP CMIP3 multimodel dataset: A new era in climate change research. Bull. Amer. Meteor. Soc., 88, 1383-1394.

Morce, C. P., J. J. Kennedy, N. A. Rayner, and P. D. Jones, 2012: Quantifying uncertainties in global and regional temperature change using an ensemble of observational estimates: The HadCRUT4 data set. J. Geophys. Res., 117, D08101, doi: 10.1029/2011JD017187.

Sato, K., J. E. Hansen, M. P. McCormick, and J. B. Pollack, 1993: Stratospheric aerosol optical depths, 1850-1990. J. Geophys. Res., 98 (D12), 22 987-22 994.

Schlesinger, M. E., and N. Ramankutty, 1994: An oscillation in the global climate system of period $65-70$ years. Nature, 367,723 726.

Semenov, V. A., M. Latif, D. Dommenget, N. Keenlyside, A. Strehz, T. Martin, and W. Park, 2010: The impact of North Atlantic-Arctic multidecadal variability on Northern Hemisphere surface air temperature. J. Climate, 23, 56685677.

Solomon, S., D. Qin, M. Marquis, K. Averyt, M. M. B. Tignor, H. L. Miller Jr., and Z. Chen, Eds., 2007: Climate Change 2007: The Physical Science Basis. Cambridge University Press, $996 \mathrm{pp}$.

Thompson, D. W. J., J. J. Kennedy, J. M. Wallace, and P. D. Jones, 2008: A large discontinuity in the mid-twentieth century in observed global-mean surface temperature. Nature, 453, 646649, doi:10.1038/nature06982.

Tung, K. K., J. Zhou, and C. D. Camp, 2008: Constraining model transient climate response using independent observations of solar-cycle forcing and response. Geophys. Res. Lett., 35, L17707, doi:10.1029/2008GL034240.

Wang, Y.-M., J. Lean, and N. R. Sheeley Jr., 2005: Modeling the sun's magnetic field and irradiance since 1713. Astrophys. J., $\mathbf{6 2 5}, 522-538$.

Wei, W. W., and G. Lohmann, 2012: Simulated Atlantic multidecadal oscillation during the Holocene. J. Climate, 25, 6989-7002.

Woodward, W. A., and H. L. Gray, 1995: Selecting a model for detecting the presence of a trend. J. Climate, 8, 1929-1937.

Wu, Z., and N. E. Huang, 2009: Ensemble empirical mode decomposition: A noise-assisted data analysis method. Adv. Adapt. Data Anal., 1, 1-14.

,-- J. M. Wallace, B. V. Smoliak, and X. Chen, 2011: On the time-varying trend in global-mean surface temperature. Climate Dyn., 37, 759-773, doi:10.1007/s00382-011-1128-8.

Zhang, R., and Coauthors, 2013: Have aerosols caused the observed Atlantic multidecadal variability? J. Atmos. Sci., in press. 